\title{
Modelling of the thermal behaviour of heat pipes
}

\author{
B. Fadhl, L. C. Wrobel \& H. Jouhara \\ School of Engineering and Design, Brunel University, UK
}

\begin{abstract}
Interest in the use of heat pipe technology for heat recovery and energy saving in a vast range of engineering applications has been on the rise in recent years. Heat pipes are playing a more important role in many industrial applications, particularly in improving the thermal performance of heat exchangers and increasing energy savings in applications with commercial use. In this paper, a comprehensive CFD modelling was built to simulate the details of the two-phase flow and heat transfer phenomena during the operation of a wickless heat pipe or thermosyphon, that otherwise could not be visualised by empirical or experimental work. Water was used as the working fluid. The volume of the fluid (VOF) model in ANSYS FLUENT was used for the simulation. The evaporation, condensation and phase change processes in a thermosyphon were dealt with by adding a user-defined function (UDF) to the FLUENT code. The simulation results were compared with experimental measurements at the same condition. The simulation was successful in reproducing the heat and mass transfer processes in a thermosyphon. Good agreement was observed between CFD predicted temperature profiles and experimental temperature data.

Keywords: thermosyphon, computational fluid dynamics (CFD), multiphase flow, phase change material, evaporation, condensation.
\end{abstract}

\section{Introduction}

A heat pipe is a two-phase heat transfer device with a highly effective heat transfer rate through evaporating and condensing a fluid that is circulating in a sealed container. A wickless heat pipe, or a two-phase closed thermosyphon, relies on gravitational forces to return the working fluid to the evaporator. This is different from a wicked heat pipe, where the working fluid is returned from the 
condenser by capillary forces [1-4]. Heat pipes have been successfully used for waste heat energy recovery in a vast range of engineering applications, such as heating, ventilation, and air conditioning (HVAC) systems [5], ground source heat pumps [6], water heating systems [7] and electronics thermal management [8]. This is mainly because of their simple structure, special flexibility, high efficiency, good compactness, and excellent reversibility [9-12]. Thermosyphons have three sections, which are the evaporator at the bottom end, where heat is added and the liquid is vaporised, the condenser at the top end, where heat is released and the vapour is condensed, and an adiabatic section in the middle between the evaporator and condenser [13]. In a thermosyphon, heat is added to the evaporator where a liquid pool exists, changing the liquid into vapour. The high temperature and pressure cause the vapour to flow and pass through the adiabatic section toward the condenser. The vapour adjacent to the condenser's wall gives up its latent heat that is absorbed in the evaporator section. The condensed liquid is then transported back to the evaporator due to gravity [14]. Two-phase closed thermosyphons have been extensively used in many applications [15]. However, only a limited number of CFD numerical simulation studies on two-phase closed thermosyphons have been published.

Alizadehdakhel et al. [1] provided a two-dimensional model and experimental studies in which they investigated the effect of input heat flow and fill ratio of the working fluid on the performance of a two-phase closed thermosyphon. They validated their study using experimental results. Three input heat flow rates of 700,500 , and $350 \mathrm{~W}$ and three fill ratios of $0.3,0.5$, and 0.8 were considered. Under these operating conditions, they found the performance of the thermosyphon improved when the input heat flow was increased from 350 to $500 \mathrm{~W}$. Further, they discovered the best performance was at a fill ratio of 0.5 . The authors reported a term called "heat performance", which they calculated by using the following equation for different fill ratios:

$$
\eta=\frac{Q_{\text {out }}}{Q_{\text {in }}} \times 100
$$

However, this term is not usual in heat pipe publications. In general, the thermal performance term used to characterize thermodynamics at different heat throughputs is the total thermal resistance.

Legierski et al. [14] provided CFD modelling and experimental measurements of heat and mass transfer in a horizontal wick heat pipe. They investigated the effectiveness of the heat pipe thermal conductivity in a transient state during start-up of the pipe operation and during temperature increases. The authors used a heat pipe that was $200 \mathrm{~mm}$ long with $4 \mathrm{~mm}$ diameter and $25 \mathrm{~mm}$ length for the evaporator and condenser. They also used two containers, one for hot water $\left(90^{\circ} \mathrm{C}\right)$ at the evaporator section and one for cold water (ambient temperature) at the condenser section. They developed a three-dimensional CFD model to simulate the internal vapour flow. They found that the effective thermal conductivity of the wick heat pipe depended on the time in the range between $15 \times 10^{3}$ and $30 \times 10^{3} \mathrm{~W} / \mathrm{m} \mathrm{K}$, and achieved its steady-state value after 
approximately 20 to $30 \mathrm{~s}$. However, the authors did not consider in the CFD modelling the phase change material from liquid phase to vapour phase, as well as condensation in the condenser section and pool boiling in the evaporator section.

Annamalai and Ramalingam [16] carried out an experimental investigation and CFD analysis of a wick heat pipe using ANSYS CFX. The authors considered the region inside the heat pipe as a single phase of vapour and a wick region as the liquid phase. They compared the predicted surface temperature along the evaporator and condenser walls and the vapour temperature inside the heat pipe with the experimental data. This model treated the flow inside the heat pipe as a single-phase and did not include the evaporation, condensation and phase change processes.

De Schepper et al. [17] developed a model to simulate the evaporation process of a hydrocarbon feedstock in a heat exchanger. They used the VOF and UDF techniques to simulate flow boiling including the phase change process. They proposed correlations to calculate the mass and heat transfer between the phases that were able to simulate the evaporation and boiling phenomena inside the convection section of a steam cracker. This model was for the convection section in a steam-cracking furnace; however, it did not include the heat pipe system.

Lin et al. [18] built a CFD model to predict the heat transfer capability of miniature oscillating heat pipes. The effects of different heat transfer lengths and inner diameters at different heat inputs were used to analyse the heat transfer capability of MOHPs. They compared the predicted model with experimental results. This model did not visualise the internal phenomena of evaporation, condensation and phase change inside the MOHPs.

Heat pipe technology is currently still under development. However, there are limited studies on the validation of predictions for modelling closed two-phase thermosyphons or wickless heat pipes. Further, a CFD simulation of a wickless heat pipe that considers all the details of heat transfer phenomena inside the heat pipe has not yet been reported. Hence, a gap still exists for further CFD work to model a wickless heat pipe. Additionally, CFD models can reduce the amount of experimental work. Therefore, in this paper, a comprehensive CFD modelling has been employed to cover all details of two-phase flow and heat transfer phenomena during the operation of a straight wickless heat pipe. Moreover, a user-defined function (UDF) has been used to complete the FLUENT code in order to simulate the phase change material.

\section{Model description}

In this model, the commercial code ANSYS FLUENT 13.0 and the Volume of Fluid (VOF) method have been applied for the modelling of a closed two-phase thermosyphon. 


\subsection{Volume of fluid (VOF) model}

Numerical solutions based on the finite volume method are more difficult for multiphase flow than for a single-phase flow. The reasons for this difficulty are that the interfaces between the phases are not stationary and physical properties such as density and viscosity change at the interfaces between the different phases, which requires an intensive computational effort. The volume of fluid (VOF) method, therefore, has been used to solve these problems by determining the motion of all phases and defining the motion of the interfaces indirectly from this result $[17,19,20]$.

\subsection{Mass and heat transfer during the evaporation and condensation processes}

FLUENT does not have the ability to simulate the phase change material during the evaporation and condensation processes. In order to circumvent this problem, a user-defined function (UDF) has been used to complete the existing FLUENT code. This UDF is essentially required to calculate the mass and heat transfer between the liquid and vapour phases during the evaporation and condensation processes, determined by the source terms in the governing equations, particularly the continuity and energy equations. Source terms proposed by De Schepper et al. [17] have been used to calculate the mass and energy transfer. Mass sources, $S_{M}$ in the volume fraction equation and energy sources, $S_{E}$ in the energy equation used in the present work can be found in Table 1, where $T_{\text {mix }}$ and $\mathrm{T}_{\text {sat }}$ are the mixture temperature and saturation temperature, respectively, and LH stands for latent heat.

Mass and energy sources in Table 1 have been implemented in the UDF and linked to the governing equations in FLUENT. The volume fraction for each phase in the cell has been defined by the VOF model. Therefore, the evaporation process required two mass sources for the calculation of the mass transfer, eqn (1) describing the amount of mass taken from the liquid phase and eqn (2) describing the amount of mass added to the vapour phase. The same procedure takes place for the condensation process, eqn (3) and eqn (4) describing the amount of mass transfer from vapour to liquid phase.

For heat transfer, a single source term for both phases is required in the evaporation or condensation. Calculation of heat transfer has been determined by multiplying the mass source with the latent heat for evaporation or condensation, eqn (5) and eqn (6), respectively.

Furthermore, it can be seen in Table 1 that the temperature is introduced as a mixture temperature rather than liquid or vapour temperature. The reason as mentioned before is that the VOF model associates some variables such as temperature and velocity with the mixture phase, not with a specific phase. 
Table 1: Construction of mass and energy sources [17].

\begin{tabular}{|c|c|c|c|c|}
\hline $\begin{array}{l}\text { Thermal } \\
\text { Energy }\end{array}$ & $\begin{array}{ll}\begin{array}{l}\text { Phase } \\
\text { process }\end{array} & \text { Change } \\
\end{array}$ & $\begin{array}{c}\text { Temp. } \\
\text { Condition } \\
\end{array}$ & Phase & Source Term \\
\hline \multirow{4}{*}{$\begin{array}{l}\text { Mass } \\
\text { Transfer }\end{array}$} & \multirow{2}{*}{ Evaporation } & \multirow{2}{*}{$\mathrm{T}_{\text {mix }}>\mathrm{T}_{\text {sat }}$} & Liquid & $S_{M}=-0.1 \rho_{L} \alpha_{L} \frac{T_{m i x}-T_{\text {sat }}}{T_{\text {sat }}}$ \\
\hline & & & Vapour & $S_{M}=0.1 \rho_{L} \alpha_{L} \frac{T_{m i x}-T_{\text {sat }}}{T_{\text {sat }}}$ (2) \\
\hline & \multirow{2}{*}{ Condensation } & \multirow{2}{*}{$\mathrm{T}_{\text {mix }}<\mathrm{T}_{\text {sat }}$} & Liquid & $S_{M}=0.1 \rho_{V} \alpha_{V} \frac{T_{s a t}-T_{m i x}}{T_{s a t}}$ \\
\hline & & & Vapour & $S_{M}=-0.1 \rho_{V} \alpha_{V} \frac{T_{\text {sat }}-T_{m i x}}{T_{\text {sat }}}$ \\
\hline \multirow{2}{*}{$\begin{array}{c}\text { Heat } \\
\text { Transfer }\end{array}$} & Evaporation & $\mathrm{T}_{\text {mix }}>\mathrm{T}_{\text {sat }}$ & \multicolumn{2}{|r|}{$S_{E}=-0.1 \rho_{L} \alpha_{L} \frac{T_{m i x}-T_{\text {sat }}}{T_{\text {sat }}} L H$} \\
\hline & Condensation & $\mathrm{T}_{\text {mix }}<\mathrm{T}_{\text {sat }}$ & \multicolumn{2}{|r|}{$S_{E}=0.1 \rho_{V} \alpha_{V} \frac{T_{s a t}-T_{m i x}}{T_{\text {sat }}} L H$} \\
\hline
\end{tabular}

\section{Simulation model}

A two-dimensional model was developed to simulate the two-phase flow and heat transfer phenomena in a thermosyphon. A total length of $500 \mathrm{~mm}$ of a closed copper tube, as can be seen in Figure 1, is used as the thermosyphon geometry, with 22 and $20.2 \mathrm{~mm}$ for the outer and inner diameters, respectively. According to the experimental condition, the thermosyphon was divided into three sections represented by the evaporator and condenser sections, with an adiabatic section between them. Both evaporator and condenser have $200 \mathrm{~mm}$ length, while the adiabatic section has $100 \mathrm{~mm}$ length.

The temperature distribution along the outer wall of the thermosyphon was monitored using eight different positions as shown in Figure 2. According to the experimental setup, $\mathrm{Te}_{1}$ and $\mathrm{Te}_{2}$ were used to record the average temperature of the evaporator section, while $\mathrm{Tc}_{1}$ to $\mathrm{Tc}_{5}$ were used to record the average temperature of the condenser section. Ta was used to record the average temperature of the adiabatic section.

Different mesh sizes were used to test grid independence. The average temperature of the evaporator ( $\left.\mathrm{T}_{\text {evap av }}\right)$ and condenser $\left(\mathrm{T}_{\text {cond av }}\right)$ sections for different mesh sizes were monitored. For the heating power of $172.87 \mathrm{~W}$, it was found that almost the same temperature differences between the evaporator and condenser sections were obtained for different mesh sizes. As a result, the mesh size of 69,092 Quad, Map cells was selected for the simulation analysis. Near the left and right walls, five layers of cells are used in order to capture the thin liquid film that develops near the wall, as shown in Figure 2. One cell layer has been used for the upper and bottom walls, as no heat conduction is considered through these walls. 


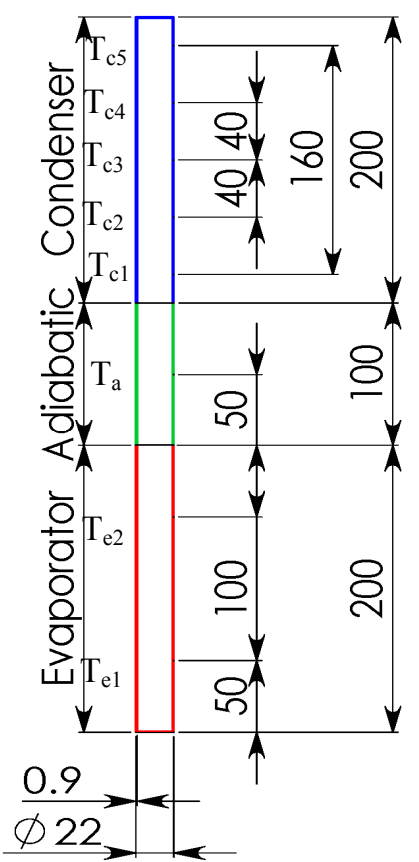

Figure 1: Geometry and dimensions.

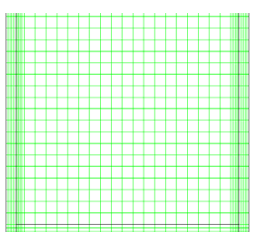

19,603

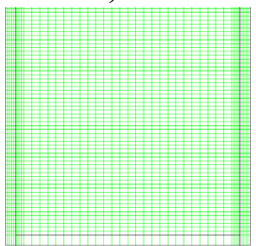

69,092

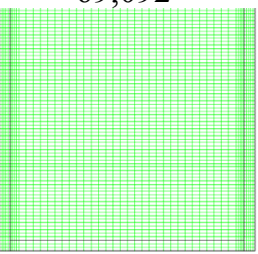

87,800

Figure 2: A section of the computational mesh.

\section{Boundary conditions}

A non-slip boundary condition is imposed at the inner walls of the thermosyphon. In order to simulate the heating and evaporation, a constant heat flux is defined at the wall boundaries of the evaporator section, depending on the power input. A zero heat flux is defined as boundary condition on the adiabatic section, assuming this section is insulated. The condenser section is cooled as a result of heat released when vapour condenses. It is assumed that the condenser is cooled by water, according to the experimental apparatus. Thus, a convection heat transfer coefficient is defined as boundary condition on the condenser's wall. The corresponding heat transfer coefficients have been calculated using the formula:

$$
h_{c}=\frac{Q_{c}}{2 \pi r L_{c}\left(T_{c, a v}-T_{\infty}\right)}
$$

where $h_{c}$ is the condenser heat transfer coefficient, $Q_{c}$ is the rate of heat transfer from the condenser, $\mathrm{L}_{\mathrm{c}}$ is the condenser height, $\mathrm{T}_{\mathrm{c}, \mathrm{av}}$ is the condenser average temperature and $T_{\infty}$ is the average temperature of the condenser cooling water. The values of $\mathrm{T}_{\infty}, \mathrm{Q}_{\mathrm{c}}$ and $\mathrm{T}_{\mathrm{c}, \mathrm{av}}$ in the above equation come from the experiments. 
The condenser heat transfer coefficients are determined based on the experimental data.

The effect of surface tension along the interface between the two phases is included by using the following equation, driven from the steam table:

$$
\sigma_{L V}=0.09805856-1.845 \times 10^{-5} T-2.3 \times 10^{-7} T^{2}
$$

where $\sigma_{L V}$ is the surface tension coefficient and $\mathrm{T}$ is the shared temperature.

The model considered water as the working fluid with a fill ratio of 0.5 (the ratio of initial liquid volume per total volume of the evaporator) and the following equation driven from the steam table is used for their density:

$$
\rho_{L}=859.0083+1.252209 T-0.0026429 T^{2}
$$

\section{Solution strategy and convergence criterion}

A transient simulation with a time step of $0.0005 \mathrm{~s}$ is carried out to model the dynamic behaviour of the two-phase flow. The time step has been selected based on the Courant number, which is the ratio of the time step to the time a fluid takes to move across a cell. For VOF models, the maximum Courant number allowed near the interface is 250 [21]. For a time step of 0.0005 , the Courant number is less than 3 . The simulation reaches a steady state after around $60 \mathrm{~s}$.

A combination of the SIMPLE algorithm for pressure-velocity coupling and a first-order upwind scheme for the determination of momentum and energy is included in the model. Geo-Reconstruct and PRESTO discretization for the volume fraction and pressure interpolation scheme, respectively, are also performed in the simulation. In the present studies, the numerical computation is considered to have converged when the scaled residual of the mass and velocity components is less than $10^{-4}$.

Water vapour is defined as the primary (vapour) phase and water liquid is defined as the secondary (liquid) phase. For the calculation of the mass and heat transfer during the evaporation and condensation processes, a temperature of $373 \mathrm{~K}$ is used as the boiling temperature and the latent heat in the UDF code is $2455 \mathrm{KJ} / \mathrm{Kg}$. When the simulation is started, the liquid pool in the evaporator is heated first. Once the saturation temperature $(373 \mathrm{~K})$ is reached, evaporation starts and phase change occurs. The saturated vapour is then transported upward to the condenser, where it condenses along the colds walls forming a thin liquid film.

\section{Simulation results}

The simulation results of the boiling and condensation processes in the thermosyphon reached a quasi-steady state after around $60 \mathrm{~s}$. Eight different positions have been used to monitor the average temperature for the evaporator, adiabatic and condenser sections. Table 2 shows the surface average temperatures in the evaporator $\left(\mathrm{Te}_{\mathrm{av}}\right)$, adiabatic $(\mathrm{Ta})$ and condenser $\left(\mathrm{Tc}_{\mathrm{av}}\right)$ sections, in addition to the thermal resistance of the system and the relative error 
$\left(\mathrm{R}_{\mathrm{E}}\right)$ between CFD simulation and experimental results (EXP). The simulation results of the VOF model showed the same trend as the experimental data. The average relative error of evaporator, adiabatic and condenser average temperatures are $7.9 \%, 9.9 \%$ and $1.9 \%$, respectively.

Figure 3 shows the experimental and simulation results of the outer surface temperature distribution along the thermosyphon for different heat inputs. The distance between 0 and $200 \mathrm{~mm}$ indicates the evaporator section. The distance between 200 and $300 \mathrm{~mm}$ indicates the adiabatic section, while the distance between 300 and $500 \mathrm{~mm}$ indicates the condenser section. The predicted CFD evaporator average temperature has deviated from the experimental results due to the consideration of a continuous heat power input along the length of the evaporator section where, in the experiment, a wire heater is evenly wrapped around the evaporator section to ensure it was not directly above a thermocouple. As shown in Figure 3, the condenser section temperature shows better agreement with the experimental results. As a result of no heat loss in the adiabatic section, the temperature is raised in the surface of this section due to the axial conduction heat transfer.

Table 2: $\quad$ Comparison between experimental data and CFD simulation for different heat inputs.

\begin{tabular}{|c|c|c|c|c|c|c|c|c|c|c|c|}
\hline \multirow{2}{*}{$\begin{array}{c}\text { Source } \\
Q_{\text {in }}\end{array}$} & \multicolumn{3}{|c|}{ Evaporator } & \multicolumn{3}{|c|}{ Adiabatic } & \multicolumn{3}{|c|}{ Condenser } & \multicolumn{2}{|c|}{$\begin{array}{l}\text { Thermal } \\
\text { Resistance }\end{array}$} \\
\hline & $\begin{array}{l}\mathrm{Te}_{\mathrm{av}} \\
\mathrm{EXP}\end{array}$ & $\begin{array}{c}\mathrm{Te}_{\mathrm{av}} \\
\mathrm{CFD}\end{array}$ & $\mathrm{R}_{\mathrm{E}}$ & $\begin{array}{r}\text { Ta } \\
\text { EXP }\end{array}$ & $\begin{array}{r}\mathrm{Ta} \\
\mathrm{CFD}\end{array}$ & $\mathrm{R}_{\mathrm{E}}$ & $\begin{array}{l}\mathrm{Tc}_{\mathrm{av}} \\
\mathrm{EXP}\end{array}$ & $\mid \begin{array}{c}\mathrm{Tc}_{\mathrm{av}} \\
\mathrm{CFD}\end{array}$ & $\mathrm{R}_{\mathrm{E}}$ & $\mathrm{R}_{\mathrm{EXP}}$ & $\mathrm{R}_{\mathrm{CFD}}$ \\
\hline W & K & K & $\%$ & K & K & $\%$ & K & K & $\%$ & $\mathrm{~K} / \mathrm{W}$ & $\mathrm{K} / \mathrm{W}$ \\
\hline 100.41 & 343 & 376.18 & 9.67 & 321.25 & 363.25 & 13.07 & 312.412 & 328.35 & 5.10 & 0.3046 & 0.4763 \\
\hline 172.87 & 341.6 & 378.37 & 10.76 & 327.45 & 362.41 & 10.68 & 318.07 & 326.96 & 2.80 & 0.1361 & 0.2974 \\
\hline 225.25 & 348.1 & 379.92 & 9.14 & 331.05 & 364.94 & 10.24 & 320.55 & 323.47 & 0.91 & 0.1223 & 0.2506 \\
\hline 275.6 & 356.1 & 381.6 & 7.16 & 335.55 & 365.62 & 8.96 & 325.95 & 327.36 & 0.43 & 0.1094 & 0.1967 \\
\hline 299.52 & 358.75 & 382.41 & 6.60 & 336.25 & 365.46 & 8.69 & 323.91 & 324.81 & 0.28 & 0.1163 & 0.1923 \\
\hline 376.14 & 370.2 & 385.06 & 4.01 & 342.75 & 370.11 & 7.98 & 330.33 & 323.96 & 1.93 & 0.1060 & 0.1624 \\
\hline \multicolumn{3}{|c|}{ Average relative error $\%$} & 7.89 & & & 9.94 & & & 1.91 & & \\
\hline
\end{tabular}




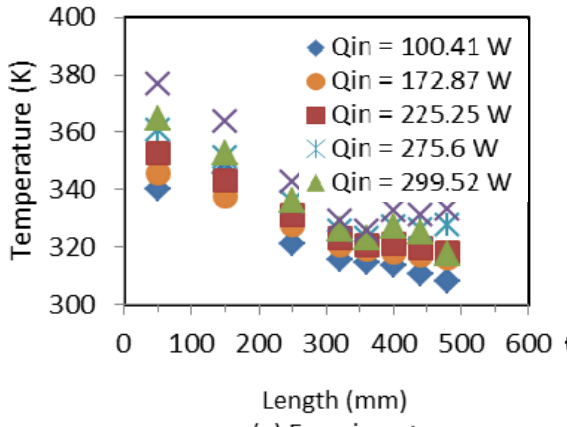

(a) Experiment

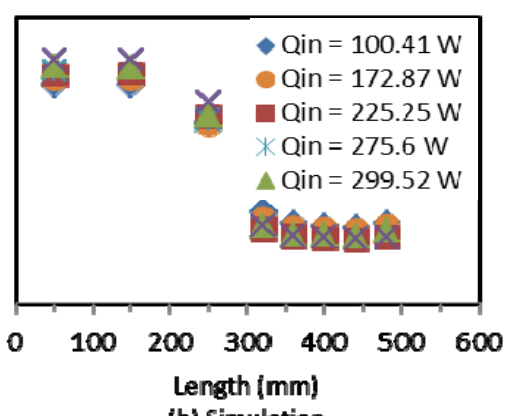

(b) Simulation

Figure 3: Temperature comparison between experiments and simulations for different heat inputs.

\subsection{Performance of a closed two-phase thermosyphon}

The performance of a thermosyphon can be characterised by the overall thermal resistance. The overall rate of heat transfer to the system $\dot{Q}$ is proportional to the effective temperature difference between the heat source to the evaporator and the heat sink from the condenser, and inversely proportional to the equivalent thermal resistance to heat transfer between the two regions. The overall rate of heat transfer can be defined as:

$$
\dot{Q}=\frac{\Delta T}{R}
$$

Hence, the effective overall thermal resistance of a thermosyphon $R$ is calculated using the following equation:

$$
R_{C F D}=\frac{T e_{a v C F D}-T c_{a v C F D}}{Q_{i n}}
$$

where $\mathrm{Te}_{\mathrm{av}} \mathrm{CFD}$ and $\mathrm{Tc}_{\mathrm{av}} \mathrm{CFD}$ are the average temperature in the evaporator and condenser, respectively, and $\mathrm{Q}_{\text {in }}$ is the heating power input. Different heating power inputs have been used to investigate the performance of a closed two-phase thermosyphon. Figure 4 illustrates that the predicted thermal resistance is in good agreement with the experimental data as the thermal resistance of the thermosyphon decreases with increasing heating power load. For heating powers above $170 \mathrm{~W}$, the thermal resistance stays relatively independent of the heating power input rate. For lower heating inputs, the thermal resistance tends to increase. In summary, the CFD simulation results are able to show the variation trends of the thermal performance of the thermosyphon for different heat throughputs. 


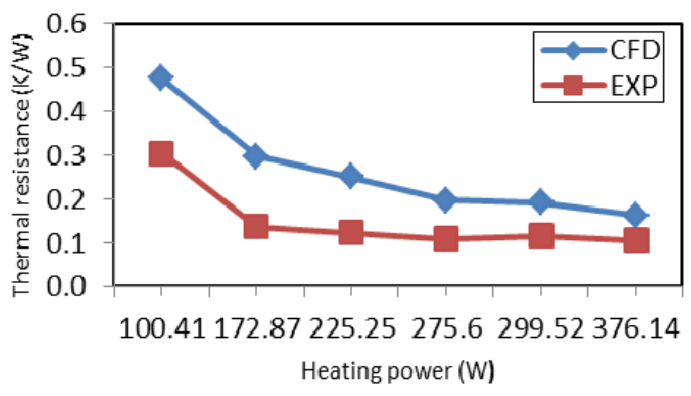

Figure 4: Relationship between thermal resistance and heating power.

\section{Flow visualisation of CFD simulation}

Figures 5 and 6 show the volume fraction contours of pool boiling in the evaporator and condensed liquid film in the condenser, respectively, for a heating power of $172.87 \mathrm{~W}$. A red colour illustrates the presence of only vapour (vapour volume fraction $=1$ ), while a blue colour stands for the presence of only liquid (vapour volume fraction $=0$ ). In Figure 6 , focus is made on the condensed liquid film in the lower region of the condenser. At the beginning of the process, the liquid pool that initially filled half of the evaporator was heated by imposing a constant heat input. At positions where the liquid reached the boiling temperature, the liquid starts to evaporate and phase change occurs as shown in Figure 5. This continuous evaporation of liquid results in a decrease in the liquid volume fraction and an increase of the vapour volume fraction. At those positions where the liquid evaporates, bubbles are formed and transported toward the top region of the liquid pool.

Following the above process, saturated vapour is transported upward to the condenser. As the vapour reaches the condenser's wall, where a convection heat transfer coefficient boundary condition is defined, as shown in Table 3, the vapour condenses along the cold walls forming filmwise condensation as shown in Figure 6. This liquid will then fall back to the evaporator section and recharge the liquid pool.

As shown in Figure 7, the temperature contours during the thermosyphon operation have been recorded. The heating power is $172.87 \mathrm{~W}$. At the beginning, the temperature in the evaporator section increased due to the heating power input, as shown in Figure $7(0.5 \mathrm{~s}$ and $1 \mathrm{~s})$. When the temperature of the evaporator section reached the boiling temperature, the phase change begins. The region of high temperature in the evaporator section expands due the vapour moving upward, as shown in Figure 7 (1.5 s to $3 \mathrm{~s}$ ). As the heating power in the evaporator section continues, the vapour flows across the adiabatic section to the condenser section, as shown in Figure 7 (4 s and $5 \mathrm{~s}$ ). Then, a high temperature region appears in the condenser section due to the vapour reaching this section, as shown in Figure 7 (10 s). The high temperature of the condenser section starts to decrease, corresponding to vapour condensing to liquid and, with 
the help of gravity, the condensed liquid falls back to the evaporator section. The above cycle describes the process of heat transfer during the operation of the thermosyphon. After that, the temperature distribution inside the thermosyphon becomes uniform as shown in Figure 7 (30 s to $60 \mathrm{~s}$ ).

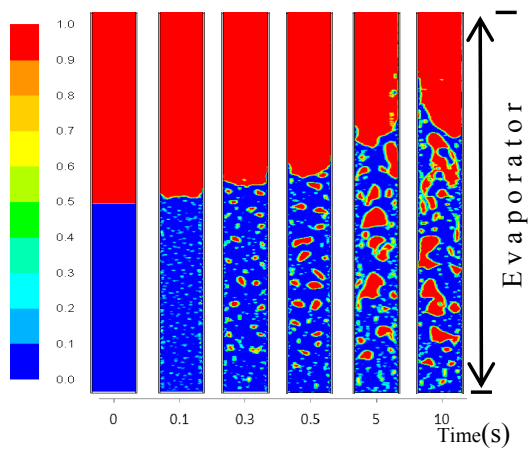

Figure 5: Contours of volume fraction of condensed liquid film in the lower region of condenser at different times.

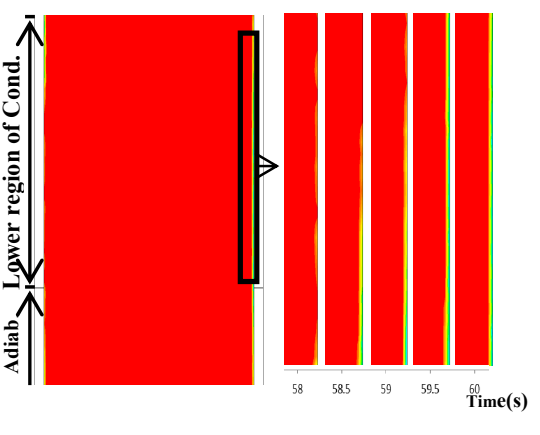

Figure 6: Contours of volume fraction of pool boiling in the evaporator section at different times.

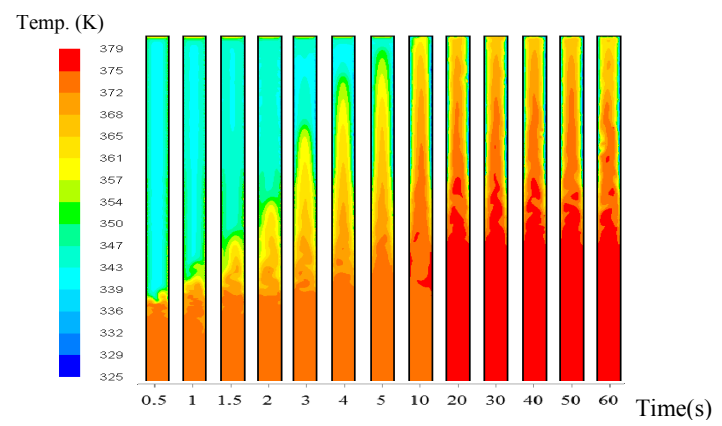

Figure 7: Temperature contours at different times.

\section{Conclusions}

The main objective of this work is the development of a CFD model that allows to perform simulations of the evaporation and condensation phenomena in a thermosyphon. The simulation of these processses is one of the steps required to model the complete system in order to consider the phase change material by implementing the appropriate source terms in the flow governing equations. These source terms, determining the mass and heat transfer between the liquid 
and vapour phases, have been linked to the main hydrodynamic equations of FLUENT.

The CFD results of this work show that FLUENT with the VOF method can successfully model the complex phenomena inside the thermosyphon. From the flow visualisation, it is found that the CFD simulation was able to reproduce the operation of the thermosyphon, including the pool boiling in the evaporator section and the condensed liquid film in the condenser section.

The average surface temperature along the thermosyphon has been compared with the experimental results at the same condition, showing that the predicted results agreed with the experimental results quite well. The thermal performance of the thermosyphon has also been characterised at different heat throughputs by the effective overall thermal resistance, and it is found that increasing the heating power inputs above $172 \mathrm{~W}$ has improved the thermal performance of thermosyphon.

\section{References}

[1] Alizadehdakhel A, Rahimi M, Alsairafi AA. CFD modeling of flow and heat transfer in a thermosyphon. International Communications in Heat and Mass Transfer 2010; 37: 312-318.

[2] ESDU. Heat pipes - general information on their use, operation and design. ESDU Manual 800131980.

[3] Faghri A. Heat Pipe Science and Technology, Taylor \& Francis: Washington, D.C., 1995.

[4] Dunn P, Reay DA. Heat Pipes, Pergamon Press: New York, 1994.

[5] Kerrigan K, Jouhara H, O’Donnell GE, Robinson AJ. Heat pipe-based radiator for low grade geothermal energy conversion in domestic space heating. Simulation Modelling Practice and Theory 2011; 19: 1154-1163.

[6] Jouhara H, Meskimmon R. Experimental investigation of wraparound loop heat pipe heat exchanger used in energy efficient air handling units. Energy 2010; 35: 4592-4599.

[7] Mathioulakis E, Belessiotis V. A new heat-pipe type solar domestic hot water system. Solar Energy 2002; 72: 13-20.

[8] Weng Y-, Cho H-, Chang C-, Chen S-. Heat pipe with PCM for electronic cooling. Applied Energy 2011; 88: 1825-1833.

[9] Jouhara H. Economic assessment of the benefits of wraparound heat pipes in ventilation processes for hot and humid climates. International Journal of Low-Carbon Technologies 2009; 4: 52-60.

[10] Parand R, Rashidian B, Ataei A, Shakiby K. Modeling the transient response of the thermosyphon heat pipes. Journal of Applied Sciences 2009; 9: 1531-1537.

[11] Ochsner K. Carbon dioxide heat pipe in conjunction with a ground source heat pump (GSHP). Applied Thermal Engineering 2008; 28: 2077-2082.

[12] Du J, Bansal P, Huang B. Simulation model of a greenhouse with a heatpipe heating system. Applied Energy 2012; 93: 268-276. 
[13] Cengel Y.A. Heat Transfer: A Practical Approach. McGraw-Hill: Boston; Toronto, 2003.

[14] Legierski J, Wiecek B, de Mey G. Measurements and simulations of transient characteristics of heat pipes. Microelectronics and Reliability 2006; 46: 109-115.

[15] Jiao B, Qiu L.M, Zhang X.B, Zhang Y. Investigation on the effect of filling ratio on the steady-state heat transfer performance of a vertical twophase closed thermosyphon. Applied Thermal Engineering 2008; 28: 1417-1426.

[16] Annamalai A.S, Ramalingam V. Experimental investigation and computational fluid dynamics analysis of an air cooled condenser heat pipe. Thermal Science 2011; 15: 759-772.

[17] De Schepper SCK, Heynderickx GJ, Marin GB. Modeling the evaporation of a hydrocarbon feedstock in the convection section of a steam cracker. Computers \& Chemical Engineering 2009; 33: 122-132.

[18] Lin Z, Wang S, Shirakashi R, Winston Zhang L. Simulation of a miniature oscillating heat pipe in bottom heating mode using CFD with unsteady modeling. International Journal of Heat and Mass Transfer 2013; 57: 642-656.

[19] Versteeg HK, Malalasekera W. An Introduction to Computational Fluid Dynamics; the Finite Volume Method. Second ed. 2007.

[20] Anderson JD. Computational Fluid Dynamics The Basics with Applications. McGraw-Hill: New York, 1995.

[21] ANSYS FLUENT User Guide (Release 13.0). Modelling Multiphase Flows. ANSYS, Inc., November 2010, (chapter 26), pp. 1143-1144. 